\section{Insuficiências: produção artística e dramaturgia na montagem de um espetáculo de dança}

\section{Insufficiencies: artistic production and dramaturgy in the assembly of a dance show}

\section{Maria Falkembach}

Universidade Federal de Pelotas. Instituto de Artes.

\section{Carolina da Silva}

Universidade Federal de Pelotas. Instituto de Artes.

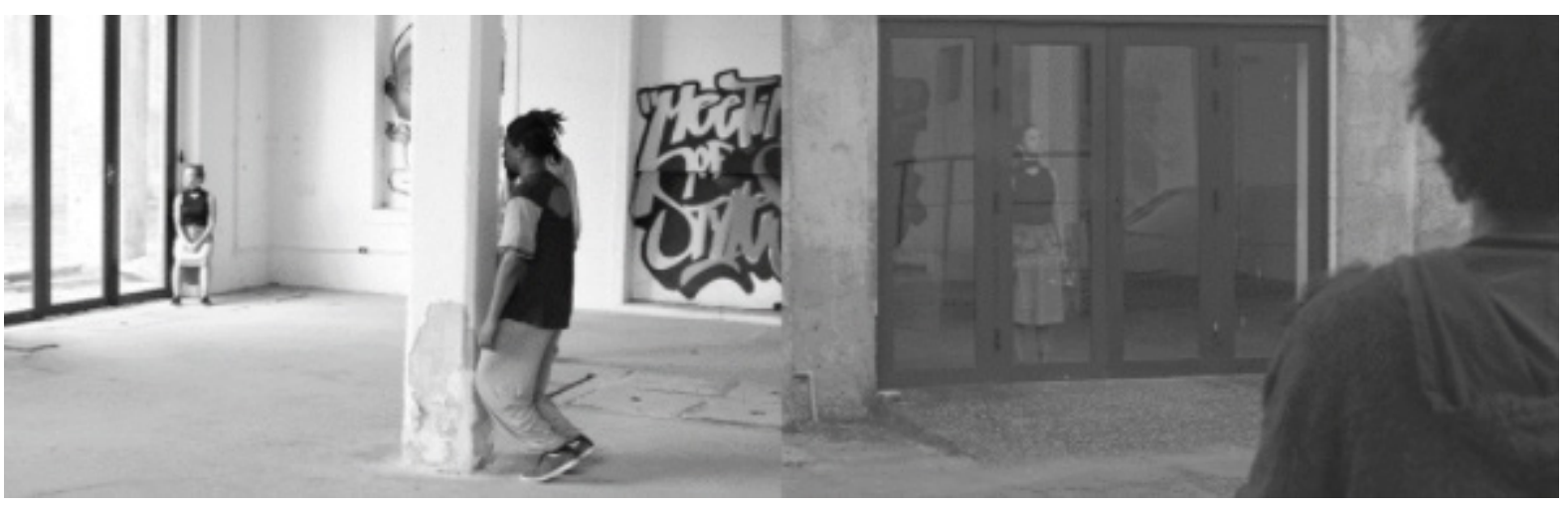

Cena 1: Vazio Cotidiano. Cena que inicia o espetáculo e traz indivíduos " olhando para dentro" em apatia isolados em seus dilemas e frustrações - Foto: Josiane Franken Corrêa e Marcos Vinícius Pinto.

Os corpos das fotos acima foram compostos numa investigação a partir de tarefa de movimento que exploraram em si e na relação com o espaço, intenções que traduzem situações de profunda apatia e "anestesia" cotidiana. Na tentativa de "preencher seus vazios" esses corpos foram sendo construídos em posturas desistidas e tipos de deslocamentos vagantes, num olhar ao longe e para "dentro de si". Essa investigação fez parte do processo de criação do espetáculo Insuficiências desenvolvida dentro da disciplina de Montagem de Espetáculo II do curso de graduação em Dança Licenciatura pela UFPEL, durante o período de construção e execução da obra em 2019.

O projeto dessa montagem elaborado no segundo semestre de 2018, na disciplina de Montagem de Espetáculo I, de modo geral trouxe como concepção cênica e tema a necessidade de falar mais profundamente sobre as insuficiências cotidianas, o que move internamente esse sentimento de frequente insatisfação, suas relações com a forma que o indivíduo se coloca no mundo e se relaciona com o outro, nesse jogo de aceitação de sua condição enquanto ser singular e inacabado.

Assim, o presente trabalho pretende apresentar a produção artística de forma visual e conceitual no que diz respeito a alguns caminhos dos processos de criação e finalização da obra, apresentando a poética resultante através de fotografias do espetáculo. Um espetáculo com a proposta de Dança Contemporânea e Dança Teatro minimalista, sutil e intensa.

\section{IMPULSO DE CRIAÇÃO: DANÇAR O VAZIO}

A partir de atravessamentos criativos e conflitos internos que surgiram por meio das reflexões, pesquisas de movimento e outras composições coreográficas ocorridas durante todo meu percurso na graduação em dança, a escolha do tema sobre insuficiências - o vazio existencial - foi impulsionada na busca de reconhecer, questionar, identificar esses diversos disparadores que fazem esse sentimento ser um dos mais atuais "bloqueadores emocionais" na vida cotidiana.

De modo geral, o espetáculo apresenta questões particulares de cada intérprete relacionadas a esse tema e também como ele reverbera no coletivo da sociedade. $\mathrm{Na}$ foto a seguir identificamos a intenção dos movimentos que foram construídas 
em frases corporais individuais, buscando tipos de desequilíbrios e quedas com foco no esvaziamento através de exercícios de respiração intensa, isto é, contrações com intenção da falta do ar gerando corpos em desequilíbrios e quedas, "esvaziados de $\mathrm{si}^{\prime \prime}$.

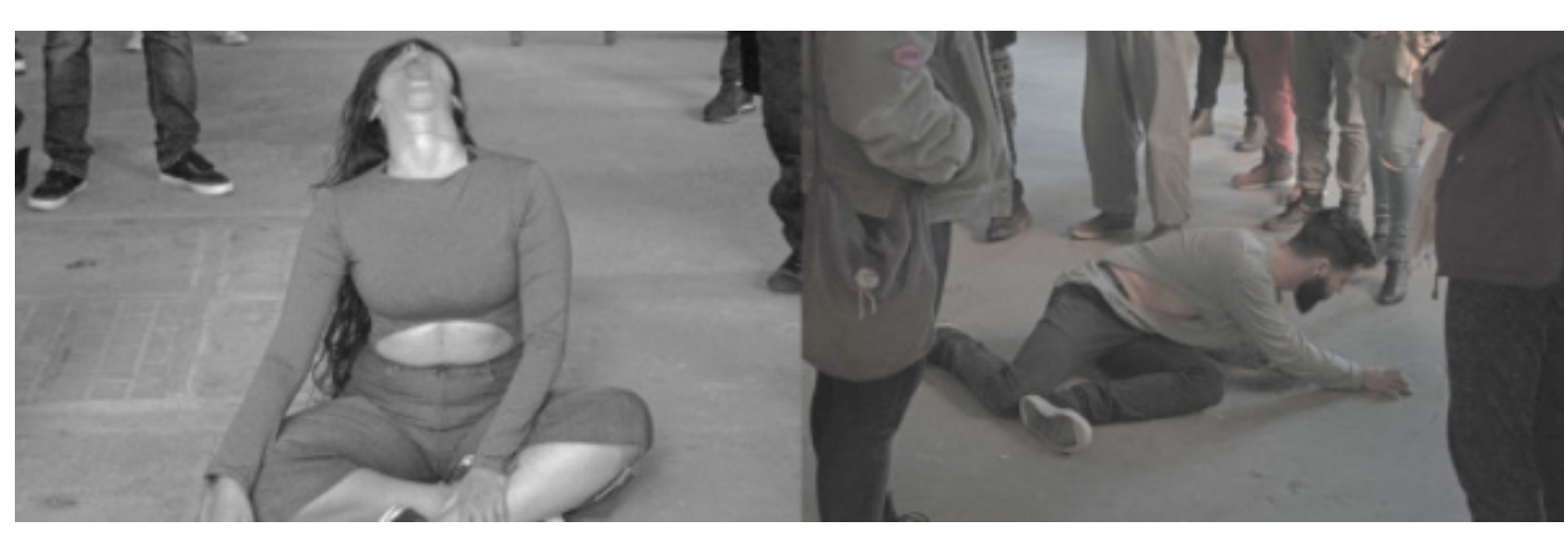

Cena 2: Vazio da Alma. Apresenta o esvaziamento da alma, a presença da falta Foto: Josiane Franken Corrêa e Marcos Vinícius Pinto.

Todos nós, em algum momento da vida, vivenciamos o sentimento de que deveríamos ter feito mais ou melhor, ter agido de outra forma, ter sido melhor pessoa, mais assertiva, mais confiante, ter dito o que pensava ou não. Esse sentimento de busca de tal "perfeição" e de auto responsabilização é natural e saudável, característica do "ser inacabado" que somos. No entanto, chegamos ao extremo da insatisfação quando a sensação, o incômodo da inadequação, da falta, nunca passa. Daí o vazio, falta o ar, sufoca-se o Ser.

$\mathrm{Na}$ foto a seguir, imagem de um momento da cena 3, foi composta inspirada na principal fonte criativa do espetáculo: a obra Albert György, a escultura "Melancolia" que apresenta um ser esburacado, sem centro e cabisbaixa, em postura prostrada. Os intérpretes forma instigados a criar a partir da estética, sensação e o movimento que a imagem sugere, trazendo uma relação com o "olhar do outro", um sufocamento social pelo julgamento de como o outro nos enxerga. Essa relação no espetáculo se 232

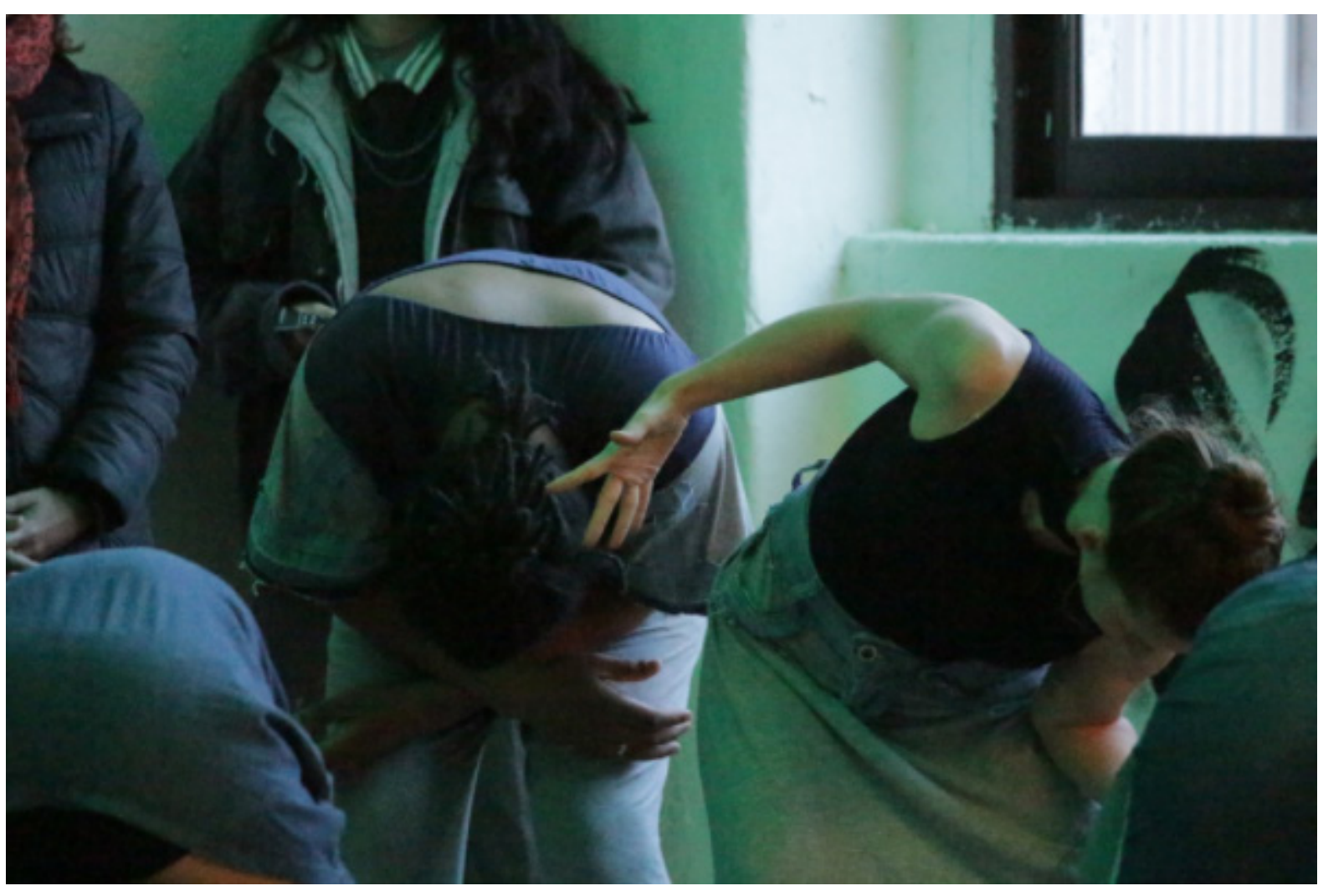

Cena 3: O Julgamento. O que tenho do outro, no outro... Insuficiências a partir do olhar do outro (direta relação com o público) - Foto: Josiane Franken Corrêa e Marcos Vinícius Pinto.

Quanto mais aprofundamos o processo de observação, tanto de nós mesmos quanto de como funciona as relações dos seres humanos na sociedade percebemos como sua estrutura é fundamentada no medo e esse medo produz uma ânsia de segurança e auto aceitação. Buscamos mecanismos, conscientes ou inconscientes, de algo que amenize esse estado de insegurança para nos sentirmos mais adequados, mais plenos, satisfeitos com nossas escolhas. Entretanto, o sentimento de vazio é constantemente realimentado, pois nossa sociedade é uma fábrica de desejos condicionados e ilusórios para distrair dessa sensação de falta, de inadequação, de não inteireza do ser singular que somos.

Através dessas reflexões, conceitos e ideias sobre o universo psicológico do espetáculo, questiona-se: $\mathrm{O}$ que é que move internamente o sentimento de frequente 
insatisfação, o estado permanente de incompletude? Por que o ser humano cada vez mais tem dificuldade em lidar com a sensação e o incômodo da inadequação e, ao mesmo tempo, por que julga o outro a partir de suas próprias frustações? Ao perceber a falência de muitas coisas que projetamos como um ideal inalcançável, somos jogados a um estado inconsciente de insatisfação, de tédio e de sufocamento social.

\section{A DRAMATURGIA E ESTRUTURA POÉTICA DA OBRA}

A noção de dramaturgia na dança não se restringe necessariamente à de uma história a ser contada, mas é construída num estado de encontros, num desenho de forças no corpo (Meyer, 2016, p. 48).

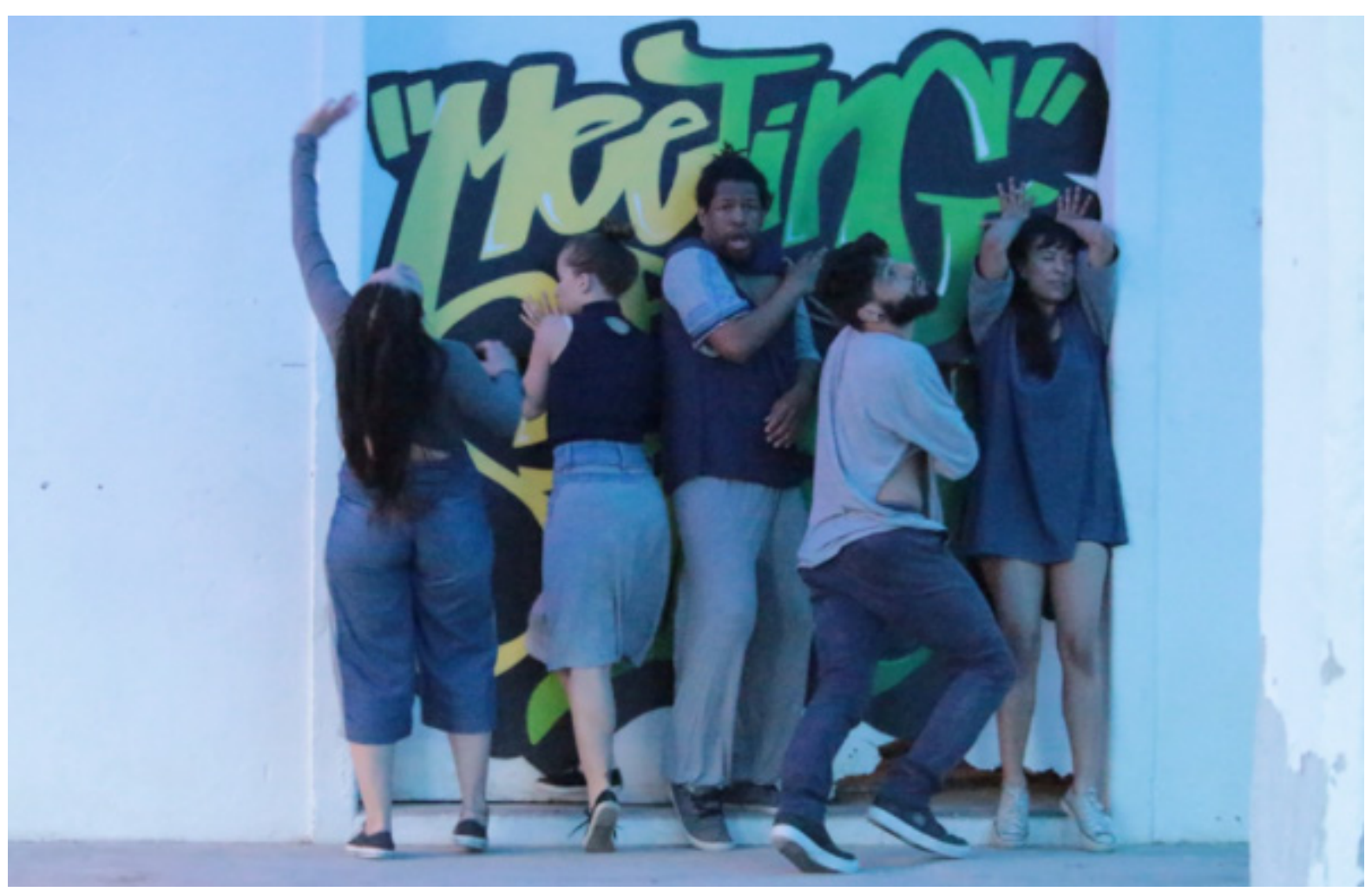

Cena 4: O que me põe na parede. Desabafo... o que não me deixa respirar! - Foto: Josiane Franken Corrêa e Marcos Vinícius Pinto.

A imagem da cena 4 (acima) apresenta corpos em angústia e exaustão onde as investigações de movimentos partiram das variações de repetição tantos das frases 234 corporais quanto verbais (texto produzido pelos intérpretes e repetidos na cena). Produz uma transformação constante, onde "o que me põe na parede" transborda na ação e reação, do espaço no corpo, dos dilemas com a parede. O espetáculo Insuficiências apresenta uma estrutura baseada no conceito de dramaturgia em dança, entendido como as tramas e conexões entre tema, ideias, estímulos, imagens e, principalmente, as ações do corpo que organizam e "tecem" um texto corpóreo na cena, no palco.

Nesse sentido, compreende-se que a dramaturgia na dança não se preocupa diretamente com o significado do movimento, mas sim com a "ação do sentido". O sentido seria um "efeito ou um acontecimento" em dança, onde o corpo não representa, "mas é percebido e vivido pelo artista e pelo espectador numa dimensão mais complexa" (Meyer, 2016).

As questões referentes ao tema são abordadas com o princípio de trazer as situações particulares dos intérpretes/criadores como "fio" condutor de narrativa e tensão. A criação partiu dos processos internos de cada um e de como eles puderam compor essas tensões por via da ação de um corpo posto a dilemas e conflitos, frente a todas questões e estímulos que, em princípio, aconteceu através dos referencias estéticos e poéticos, ou seja, fontes escolhidas para as várias atividades no início do processo de ensaio e criação. Trata-se dos materiais utilizados para fazer os intérpretes e a equipe entrar em contato com o universo do espetáculo a partir de textos, material audiovisual, sensações, sonoridades, perguntas, imagens, histórias, enfim, tudo que leve a imaginação e memórias a uma atmosfera que permite trabalhar a sensibilidade para o tema em questão.

As fotos a seguir apresentam trechos da cena 5, Eu preciso falar, que foi composta a partir do trabalho com fontes e referências estéticos, reflexões sobre histórias e memórias das intérpretes que auxiliaram no processo criativo de uma sequência 
coreográfica em que os corpos, em uma dinâmica de repetição e em crescente tensão, movimentam-se na tentativa de "pôr para fora" o desgaste, o cansaço de seu silêncio.

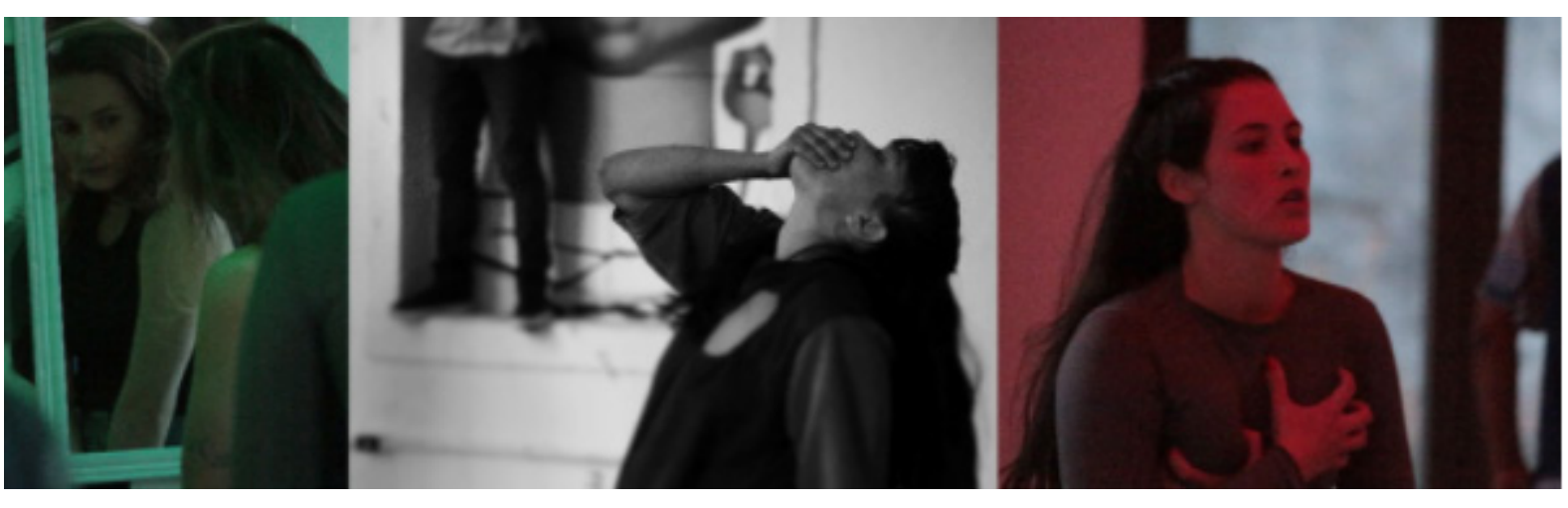

Cena 5: Eu preciso falar. Relações da mulher com seu corpo, sua imagem e o constante "silenciamento" do seu Ser - Foto: Josiane Franken Corrêa e Marcos Vinícius Pinto.

Assim, a dramaturgia da montagem Insuficiências não busca ilustrar vivências através de representação, e sim, apresenta a construção de uma narrativa singular no próprio movimento, onde articula os elementos de investigação nos processos criativos entre imagens, textos, sensações e as reverberações no corpo, no movimento. Deste modo, sua estrutura dramática tem características fragmentada, onde desenvolve picos de intensidade/tensão com quebras de foco e relaxamento (introspectivo).

\section{CONSIDERAÇÕES SOBRE O ESPAÇO CÊNICO, CENOGRAFIA E A FUNÇÃO DO ESPECTADOR}

A escolha do espaço cênico foi em busca de uma plasticidade com referência nos aspectos cinzas e de concreto, na "dureza" das relações consigo e com o outro. No início do projeto, a ideia era utilizar o espaço "Brahma" no porto de Pelotas (ao lado da livraria UFPel), com arquitetura antiga e abandonada (ruínas), pelos aspectos 236 cenográficos que lugar já propunha. No entanto, por estar interditado, surge a possibilidade do uso da "Galeria Brahma", espaço ao lado das ruínas utilizado, principalmente, para exposições de arte e outras mostras artísticas.

Assim, se mantém a idealização de um cenário do próprio espaço: a imagem das ruínas, os vidros (janelas e portas), o branco/cinza em algumas paredes e o graffiti em outras (imagens de contraste), além de elementos cênicos para as cenas como espelho, corda, escada. A maior parte do processo de criação e ensaios aconteceu no próprio lugar, facilitando o desenrolar e o diálogo das ideias com o que o ambiente instigava, a textura áspera do chão e paredes, o vazio nas brechas do espaço, o olhar através do vidro, o entardecer melancólico (a proposta de apresentações em final da tarde, buscando as nuances de iluminação natural do horário e a imagem do entardecer).

Além disso, a montagem coloca e provoca o espectador a assumir uma situação ativa, onde podemos estar dentro da cena, se deslocar pelo espaço ou não, mas principalmente, seguem e julgam os personagens, que serão constrangidos em suas ações de incapacidade e insuficiência. O público é instigado a ampliar sua percepção e desvelar os pensamento e sentimentos que estarão em jogo, vivenciando a experiência entre os corpos e o espaço, entre as imagens criadas interna e externamente.

Nasfotos a seguir, das últimas cenas, podemos identificar os corpos em mudança de intensidade/tensão e intenção criada pela pausa. A pausa do olhar, na postura sutil e vazia dos bailarinos em uma movimentação construída na investigação das "saídas" da condição insuficiente para um estado de aceitação. 


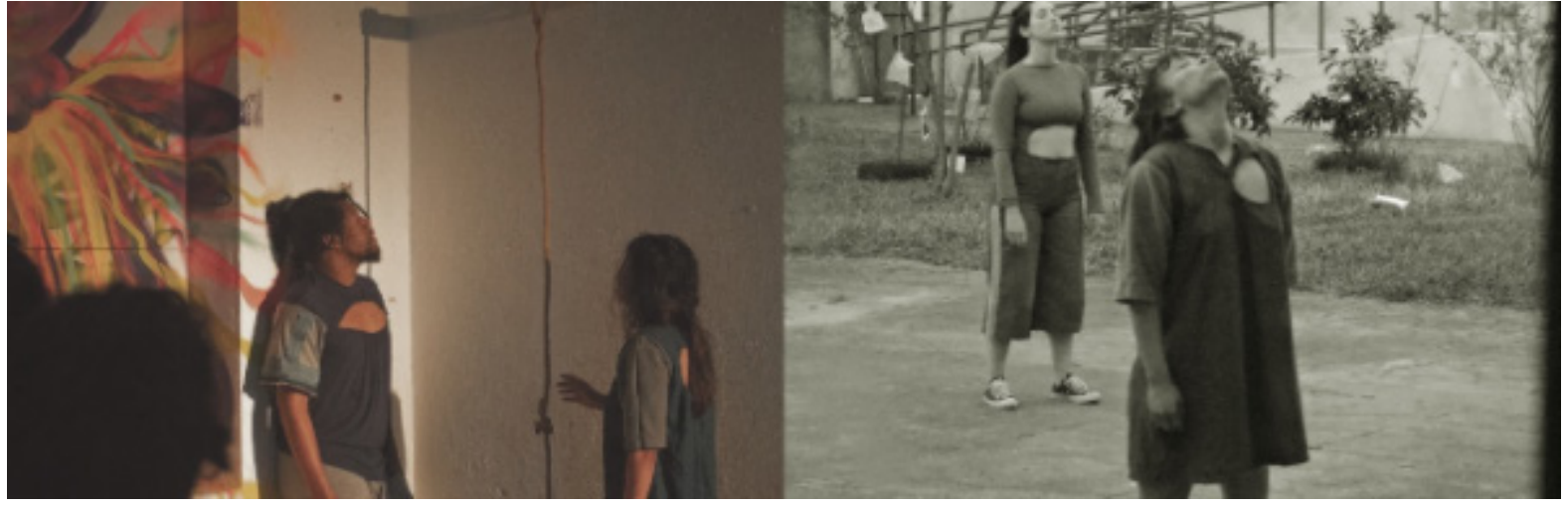

Cena 6: Suicídio. Impulso que levar o indivíduo a ter esse pensamento. Cena 7: Plenitude. Busca da energia vital, aceitação e escuta sincera de quem somos, pelas nossas capacidades e identidades - Foto: Josiane Franken Corrêa e Marcos Vinícius Pinto.

O espetáculo Insuficiências propõe trazer para cena os conflitos internos da constante busca de preencher os vazios na relação com o outro, com o espaço, falta e presença, ar e silêncio. Assim, apresenta uma dramaturgia conectada com esses pensamentos, signos e sensações e como transbordam na ação do corpo e na linguagem da dança.

\section{REFERÊNCIAS}

BOGARD, Anne; LANDAU, Tina. 0 livro dos Viewpoints: um guia prático para o viewpoints e composição. São Paulo: Perspectiva, 2017.

BOGARD, Anne. A preparação do diretor. São Paulo: Martins Fontes, 2011.

MÈLICH, Joan Carles. Entrevista com Mèlich. Revista CREARMUNDOS, 2013. Disponível em: <https://omareafilosofia.blogspot.com/2013/10/finitude-pedagogia-da-finitude.html $>$.

FAGUNDES, Patrícia. 0 processo de ensaios como mecanismo de relações: um dispositivo festivo. Anais Reunião Científica da ABRACE, Porto Alegre, 2011.
LOBO, Lenora; NAVAS, Cássia. Arte da Composição: Teatro do Movimento. Brasília: LGE,2008.

MEYER, Sandra. Elementos para composição de uma dramaturgia do corpo e da dança/Tubo de ensaio: composição [Interseções + Intervenções]. Florianópolis: Instituto Meyer Filho, 2016. P. 45 -53. 